\title{
Upregulation of circ-ASPH contributes to glioma cell proliferation and aggressiveness by targeting the miR-599/AR/SOCS2-AS1 signaling pathway
}

\author{
YI QU ${ }^{1,2 *}$ LI QI $^{3 *}$, LIGUO HAO $^{4}$ and JIAN ZHU ${ }^{1,2}$ \\ ${ }^{1}$ Department of Neurosurgery, The First Hospital of Qiqihar; ${ }^{2}$ Department of Neurosurgery, \\ Qiqihar Hospital Affiliated to Southern Medical University; ${ }^{3}$ Department of Nursing, Qiqihar Medical University; \\ ${ }^{4}$ Department of Medical Technology, Qiqihar Medical University, Qiqihar, Heilongjiang 161000, P.R. China
}

Received July 23, 2020; Accepted February 11, 2021

DOI: $10.3892 / \mathrm{ol} .2021 .12649$

\begin{abstract}
Glioma (GM) is the most common type of malignant brain tumor with a high recurrence rate. Circular RNAs (circRNAs) play a key role in mediating tumorigenesis. However, the functions and mechanisms of circRNAs in GM are still not fully understood. A circRNA microarray was performed to identify differentially expressed circRNAs in GM and non-cancerous specimens. Reverse transcription-quantitative PCR was used to detect circ-aspartyl/asparaginyl $\beta$-hydroxylase (ASPH) expression in GM tissues and cells. The clinical importance of circ-ASPH was investigated using Kaplan-Meier analysis. The functions of circ-ASPH were investigated in LN229 and U87MG cells. Bioinformatics, RNA immunoprecipitation, RNA pull-down and luciferase reporter assays were used to explore the mechanisms of circ-ASPH in GM. circ-ASPH levels were upregulated in GM specimens and cells. The prognostic role of circ-ASPH was identified in patients with GM. Loss/gain of function assays demonstrated that circ-ASPH increased cell proliferation, migration and invasion in GM cells. Mechanistically, circ-ASPH counteracted microRNA (miR)-599-mediated androgen receptor (AR) suppression by acting as a sponge for miR-599. Rescue assays indicated that circ-ASPH facilitated cell progression by regulating AR expression. Moreover, AR activated long non-coding RNA suppressor of cytokine signaling 2-antisense RNA 1 (SOCS2-AS1) expression in GM cells. Taken
\end{abstract}

Correspondence to: Dr Yi Qu, Department of Neurosurgery, Qiqihar Hospital Affiliated to Southern Medical University, 30 Gongyuan Road, Qiqihar, Heilongjiang 161000, P.R. China E-mail: music1@aliyun.com

${ }^{*}$ Contributed equally

Key words: glioma, circular RNA, circ-ASPH, miR-599, SOCS2-AS1 together, circ-ASPH/miR-599/AR/SOCS2-AS1 signaling may be a promising biomarker/therapeutic target for GM.

\section{Introduction}

Glioma (GM) is the most common type of malignant brain tumor, with high recurrence, accounting for $74.6 \%$ of all malignant central nervous system tumors in America between 2009 and 2013 (1). The morbidity of GM is higher in men (56.3\%) compared with in women (43.7\%) (2). Even with aggressive treatments, such as neurosurgical resection followed by radical combined radiochemotherapies, these notoriously infiltrative tumors invariably recur, and there has been no significant improvement in the overall survival rate of patients with GM in recent decades (3). Therefore, understanding the complex biological characteristics of GM and identifying suitable prognostic biomarkers are urgently needed.

Circular RNAs (circRNAs), a novel group of conserved RNAs, exert pivotal functions in mammalian cells (4). The present evidence demonstrates that circRNAs regulate the levels of miRNAs as sponges for miRNAs or alter gene transcription by binding to RNA-binding proteins $(5,6)$. In recent years, circRNAs have been reported to be closely associated with several diseases, such as cancer and diabetes (7-9). Moreover, they are essential for the development of GM. For example, circ-HIPK3 acts as a prognostic biomarker for GM and promotes cell aggressiveness by targeting miR-654/insulin-like growth factor 2 mRNA-binding protein 3 signaling (10). Another study indicated that circPTN sponges miR-145-5p/miR-330-5p to promote proliferation and stemness in GM (11). Androgen receptor (AR) is a transcription factor that regulates eukaryotic gene expression and affect cellular proliferation and differentiation in target tissues (12). Suppressor of cytokine signaling 2-antisense RNA 1 (SOCS2-AS1) is a type of long non-coding RNA (lncRNA) that acts as oncogenic function in human cancer progression (13). Homo sapien (hsa) circRNA_104634 is spliced from the aspartyl/asparaginyl $\beta$-hydroxylase (ASPH) gene (chr8:62593526-62596747) and the spliced length is 264 nucleotides. The current research aimed to identify the functions and possible mechanisms of hsa_circRNA_104634 (circ-ASPH) in regulating GM cell progression. 


\section{Materials and methods}

Patients and tissues. In total, 60 fresh GM/non-tumor samples were obtained during surgical resection from the patients with GM at the Qiqihar Hospital Affiliated with Southern Medical University (Qiqihar, China) from January 2014 to January 2016. The cohort consists of 60 patients (age range: 17-67 years old; 39 male, 21 female). The inclusion criteria are as following: i) The patients tissues were examined by at least two experienced pathologists; ii) the patients underwent radical resection with a clear surgical margin and the adjacent non-tumorous tissues were at least $1-\mathrm{cm}$ away from the tumor edge; iii) the patients with available follow-up information (over the phone); iv) none of the patients received anticancer treatment before the surgery and no history of other types of cancer. The exclusion criteria are that the patients with serious diseases or severe chronic diseases. Overall survival time was determined as survival time after surgery. The specimens were frozen in liquid nitrogen immediately after surgery and stored at liquid nitrogen $\left(-196^{\circ} \mathrm{C}\right)$. The project was authorized by The Ethics Committee of Qiqihar Hospital Affiliated with Southern Medical University and written informed consent was obtained from all patients. The patients were divided into high- and low-circ-ASPH groups according to the median expression level of circ-ASPH in cancer tissues.

Cell culture and transfection. GM cell lines including U251, U87MG (glioblastoma of unknown origin), LN229 and normal human astrocyte cells (NHAs) were acquired from The Cell Bank of Type Culture Collection of The Chinese Academy of Sciences or The American Type Culture Collection. The cells were cultivated in RPMI-1640 medium (HyClone; Cyvita) containing 10\% fetal bovine serum (FBS) (Gibco; Thermo Fisher Scientific, Inc.) in a $37^{\circ} \mathrm{C}, 5 \% \mathrm{CO}_{2}$ incubator.

MicroRNA (miR)-599 mimics, miR-599 inhibitor and scramble oligonucleotide were obtained from Shanghai GenePharma Co., Ltd. circ-ASPH/AR small interfering (si)RNAs and overexpression vectors were obtained from Guangzhou RiboBioCo.,Ltd. Transfection was conducted when cell confluence reached $60-80 \%$ using Lipofectamine ${ }^{\circledR} 3000$ (Invitrogen; Thermo Fisher Scientific, Inc.) according to the manufacturer's instructions. LN229 cells were used for knockdown experiments (transfection with si-circ-ASPH-1/-2 or si-NC) because it has the highest expression of circ-ASPH. U87MG cells were used for overexpression due to its lowest circ-ASPH expression (transfection with circ-ASPH vector or empty vector). The targeted sequences of siRNA-circ-ASPH are listed as follows: si-circ-ASPH-1, 5'-AGTTTTATTAGA GACAAAGCA-3' And si-circ-ASPH-2, 5'-CCAAAGTTT TATTAGAGACAA-3'. si-AR sequence was 5'-AAGAUA AUAACUCAGUUCUUATT-3'. si-NC sequence was 5'-UUC UCCGAACGUGUCACGUTT-3'. miR-599 mimics sequence was 5'-GUUGUGUCAGUUUAUCAA AC-3'. miR-599 inhibitor sequence was 5'-GUUUGAUAAACUGACACA AC-3'. Mimics-NC sequence was 5'-UUCUCCGAACGU GUCACGU-3'. Inhibitor-NC sequence was 5'-CAGUACUUU UGUGUAGUACAA-3'. In total, $5 \mu 1$ of siRNA $(20 \mu \mathrm{M})$ or $2.5 \mu \mathrm{g}$ of plasmid vector with $5 \mu \mathrm{l}$ of $\mathrm{P} 3000^{\mathrm{TM}}$ reagent was diluted in $125 \mu 1$ serum-free medium. After 5 min of incubation at $22-25^{\circ} \mathrm{C}$, the reagents in the two tubes were combined.
After 15-20 min, the mixtures were added into a six-well plate with serum-free medium. Following $8 \mathrm{~h}$ of incubation at room temperature, the medium was r-eplaced with medium containing 10\% FBS (Gibco; Thermo Fisher Scientific, Inc.). Total RNA isolation was performed at $48 \mathrm{~h}$ after transfection. Protein extraction was conducted at $72 \mathrm{~h}$ after transfection.

circRNA sequencing. Total RNA from 4 pairs of tumor/adjacent nontumorous tissues was extracted using TRIzol ${ }^{\circledR}$ (Invitrogen; Thermo Fisher Scientific, Inc.) following the manufacturer's instructions. Non-circular RNAs were digested by ribonuclease R. circRNAs were amplified and transcribed into fluorescent cRNA by the random priming method (14). Arrays were scanned using the Illumina sequencing platform (Illumina, Inc.).

Reverse transcription-quantitative (RT-q)PCR. Total RNA from GM specimens and cells was obtained using TRIzol reagent. Reverse transcription assay was performed using SuperScript RT kit in accordance with the manufacturer's protocol (Invitrogen; Thermo Fisher Scientific, Inc.). The reaction was set at $25^{\circ} \mathrm{C}$ for $10 \mathrm{~min}, 42^{\circ} \mathrm{C}$ for $60 \mathrm{~min}, 85^{\circ} \mathrm{C}$ for 5 min. SYBR-Green qPCR master mix (Invitrogen; Thermo Fisher Scientific, Inc.) was applied to conduct RT-qPCR. The reaction volume was $10 \mu \mathrm{l}$. The thermocycling conditions were as follows: $90^{\circ} \mathrm{C}$ For $5 \mathrm{~min}$, then $90^{\circ} \mathrm{C}$ for $15 \mathrm{sec}, 60^{\circ} \mathrm{C}$ for $30 \mathrm{sec}$ for 45 cycles. The $2^{-\Delta \Delta \mathrm{Cq}}$ method was employed to analyze gene expression (15). For circRNA and mRNA quantification, GAPDH was used as the internal reference. For miRNA (small non-coding RNA) quantification, U6 was used as the internal control. The primers for circ-ASPH, GAPDH and U6 were as follows: circ-ASPH: 5'-AACTTATCAGAG GTGCTTCAAGG-3' (Forward) and 5'-GAAGTTCCTGAG AGTCCGCC-3' (reverse), ASPH: 5'-CATGGAGGACAC AAGAATGGG-3' (forward) and 5'-CCAAACGACAGCTAC AGATGT-3' (reverse), AR: 5'-GACGACCAGATGGCTGTC ATT-3' (forward) and 5'-GGGCGAAGTAGAGCATCCT-3' (reverse), SOCS2-AS1: 5'-CCATACAGGTCAACTTTTCCA CCAC-3' (forward) and 5'-CCAACCTCAGCTCTGCTCTCT T-3' (reverse), GAPDH: 5'-GGGAGCCAAAAGGGTCAT-3' (forward) and 5'-GAGTCCTTCCACGATACCAA-3' (reverse), miR-599: 5'-GTTGTGTCAGTTTATCAAAC-3' (forward) and 5'-\% CTCCATATCGCACTTTAATCTCTAACT-3' (reverse), U6: 5'-ATTGGAACGATACAGAGAAGATT-3' (forward) and 5'-GGAACGCTTCACGAATTTG-3' (reverse).

Treatment of Actinomycin D. After cell inoculation in six-well plates $\left(2.5 \times 10^{5} /\right.$ well $)$, the transcriptional inhibitor actinomycin D (EMD Millipore) was added to the culture medium at $2 \mathrm{mg} / \mathrm{ml}$ for respective $0,4,8,12$ and $24 \mathrm{~h}$. Then, total RNA was extracted and RT-qPCR was used to detect the expression of circ-ASPH and linear ASPH mRNA as aforementioned. The detection methods used for RNA isolation and RT-qPCR were identical to aforementioned.

Subcellular fractionation test. A PARIS kit (cat. no. AM1921; Thermo Fisher Scientific, Inc.) was used to separate RNAs in the cytoplasmic and nuclear fractions in accordance with the manufacturer's instructions, followed by RT-qPCR with U6 and GAPDH as the nuclear and cytoplasmic controls, respectively. 
RNA immunoprecipitation (RIP). A RIP assay was conducted using the Magna RIP RNA-Binding Protein Immunoprecipitation kit (EMD Millipore). GM cells were transfected for $48 \mathrm{~h}$. The adherent cells were cultured until $80-90 \%$ confluency in dishes. In total, $2.0 \times 10^{7}$ cells were lysed using $200 \mu \mathrm{l}$ complete RIP lysis buffer (EMD Millipore). The cell lysates were incubated with $50 \mu 1$ magnetic beads protein A/G conjugated with $5 \mu \mathrm{g}$ antibodies against Argonaute 2 (anti-Ago2; 1:30; cat. no. ab186733; Abcam) or IgG (anti-IgG; 1:50; cat. no. PP64B; EMD Millipore) for $30 \mathrm{~min}$ at room temperature. Then $900 \mu \mathrm{l}$ of RIP immunoprecipitation buffer was added to each tube, which were incubated with rotation for $6 \mathrm{~h}$ at $4^{\circ} \mathrm{C}$. The beads were then washed and incubated with $150 \mu 1$ proteinase $\mathrm{K}$ buffer for RNA purification at $55^{\circ} \mathrm{C}$ for 30 min with shaking to digest the protein. After purification, enriched circ-ASPH was quantified using RT-qPCR as aforementioned.

RNA pull-down assay. In total, 100 pmol biotin-labeled circ-ASPH and oligonucleotide probes were incubated with $50 \mu \mathrm{l}$ of magnetic streptavidin beads (cat. no. 20164; Thermo Fisher Scientific, Inc.) for $2 \mathrm{~h}$ at 22-25 ${ }^{\circ} \mathrm{C}$. LN229 and U87MG cells were lysed using Pierce IP Lysis Buffer (Thermo Fisher Scientific, Inc.) according to the manufacturer's manual. RNAs wer purified with TRIzol and the lysed samples were sonicated. The sonication procedure is five series of $30 \mathrm{sec}$ on $(20 \mathrm{kHz})$ and $30 \mathrm{sec}$ off at $4^{\circ} \mathrm{C}$. Immediately after sonication, samples were centrifuged for $5 \mathrm{~min}$ at $12,000 \mathrm{x} \mathrm{g}$ at $4^{\circ} \mathrm{C}$. After adding hybridization buffer to the supernatants, $20 \mu \mathrm{l}$ of samples were then incubated overnight with the magnetic bead mixture at $4^{\circ} \mathrm{C}$. The supernatant was discarded and beads were washed with $900 \mu \mathrm{l}$ of wash buffer. In total, $95 \mu \mathrm{l}$ of proteinease $\mathrm{K}$ buffer and $5 \mu \mathrm{l}$ of proteinase-K were added to the samples. The samples were incubated for $45 \mathrm{~min}$ at $50^{\circ} \mathrm{C}$ then $10 \mathrm{~min}$ at $95^{\circ} \mathrm{C}$. Samples were chilled on ice for $3 \mathrm{~min}$ before separating the beads from RNAs. RNAs were purified and DNA were removed using an RNA Purification kit (cat. no. 12183555; Thermo Fisher Scientific, Inc.) in accordance with the manufacturer's instructions. After purification, enriched circ-ASPH and miRNAs were quantified by RT-qPCR. A negative control was also performed using scrambled oligonucleotide probes.

Dual-luciferase reporter assay. CircRNA Interactome (https://circinteractome.nia.nih.gov) and starBase 2.0 (http://starbase.sysu.edu.cn) were used to predict the target miRNAs of circ-ASPH (16). The target genes of miR-599 were predicted using the target gene prediction software, starBase 2.0 (17). Data from The Cancer Genome Atlas (TCGA) datasets were analyzed using starBase 2.0. Mutant (mut) or wild-type (wt) circ-ASPH and the 3'-untranslated region (UTR) of AR containing the predicted binding site for miR-599 were amplified using PCR and cloned into the pmiR-Repot vector (YouBio). Wt or mut plasmids (50 ng) were cotransfected with scrambled mimics-negative control (NC) or miR-599 mimics (20 nM; Shanghai GenePharma Co., Ltd.) into 293T (Type Culture Collection of The Chinese Academy of Sciences, Shanghai, China) cells using Lipofectamine 3000. A luciferase assay was conducted using a dual luciferase reporter assay kit (Promega Corporation) after $36 \mathrm{~h}$ of transfection according to the manufacturer's instructions. The specific target activity was expressed as the relative activity ratio of firefly luciferase to Renilla luciferase.

Immunoblotting assay. Cell lysates harvested at $72 \mathrm{~h}$ post-transfection were prepared using RIPA reagent (Beyotime Institute of Biotechnology). A BCA assay kit (Beyotime Institute of Biotechnology) was used to measure the concentration of proteins. After that, all samples were incubated in boiling water for $10 \mathrm{~min}$ to achieve protein denaturation. Then, $40 \mu \mathrm{g}$ per lane of protein from each sample was subjected to $10 \%$ SDS-PAGE electrophoresis to separate proteins with different molecular weights. Proteins were transferred to PVDF membranes, followed by blocking with non-fat milk at room temperature for $1 \mathrm{~h}$. The blocked membranes were then incubated with GAPDH (1:10,000; cat. no. ab181602) and AR (1:1,000; cat. no. ab198394) rabbit primary antibodies (both Abcam) for $12 \mathrm{~h}$ at $4^{\circ} \mathrm{C}$, followed by incubation with goat anti-rabbit IgG (HRP) secondary antibody (1:5,000; cat. no. ab6721; Abcam) at room temperature for $2 \mathrm{~h}$. ECL ${ }^{\mathrm{TM}}$ Blotting Reagent (Sigma-Aldrich; Merck KGaA) was used to develop the signals of each band.

Cell Counting Kit (CCK)-8 and clone-forming assays. Cells were seeded onto 96-well plates at 2,000 cells/well after $48 \mathrm{~h}$ of transfection. The culture medium was replaced with $90 \mu \mathrm{l}$ of fresh medium and $10 \mu \mathrm{l}$ of CCK-8 reagent (Shanghai Yeasen Biotechnology Co., Ltd.) at the indicated time points $(0,24,48,72$ and $96 \mathrm{~h})$. Absorption was detected at $450 \mathrm{~nm}$ using a microplate reader (Thermo Fisher Scientific, Inc.). For the clone-forming assay, 800 transfected cells were suspended in RPMI-1640 medium and added to six-well plates. After culturing for 12 days, the cells were fixed with paraformaldehyde for $20 \mathrm{~min}$ at room temperature and stained with crystal violet for another $20 \mathrm{~min}$ at room temperature (Beyotime Institute of Biotechnology). Finally, the colonies were manually counted.

Scratched wound assay. A scratched wound assay was conducted as described previously (18). Briefly, LN229 and U87MG cells were seeded in a six-well plate. The sample cells were continuously cultured until the cell fusion rate reached $>90 \%$, and then medium with a low concentration of serum (1\%) was used to replace the culture medium. The scraper was aligned at the lower part of the plate and pushed up slightly to form a scratch. Images were captured at preset time points ( 0 and 36 h for LN229 cells; 0 and 24 h for U87MG cells), and cell migration rates were then calculated for each group. A light microscope was used for visualizing and capturing the images. ImageJ version 1.50i software (National Institutes of Health) was used to analyze the distance of cell migrated.

Transwell experiments. A Transwell chamber(BD Biosciences) was employed to determine cell migratory and invasive abilities. For the invasion assay, the Transwell compartment was coated with Matrigel (precooled at $4^{\circ} \mathrm{C}$ overnight) and placed in an incubator at $37^{\circ} \mathrm{C}$ for $4 \mathrm{~h}$ to form a reconstructed basement membrane. In total, $200 \mu \mathrm{l}$ of serum-free medium with the cells and $600 \mu \mathrm{l}$ of corresponding medium with $10 \%$ FBS were used for the upper and lower chambers, respectively. After $24 \mathrm{~h}$ culturing at $37^{\circ} \mathrm{C}$ in a cell incubator, the cells in the 
upper chamber were discarded, the cells on the lower side of membrane were fixed with paraformaldehyde for $20 \mathrm{~min}$ at room temperature and stained with crystal violet for another $20 \mathrm{~min}$ at room temperature. The migratory or invasive cells were assessed using a light microscope.

Statistical analysis. Data analyses were performed using SPSS 22.0 software (IBM, Corp.). For group comparisons, the differences between two groups and multiple groups were analyzed via unpaired Student's t-tests and one-way ANOVA with Tukey's test, respectively. For comparisons between cancerous and adjacent normal tissues, paired t-tests were used. Pearson's correlation analysis was carried out to examine the correlation between miR-599, circ-ASPH and AR. Survival curves were estimated by applying Kaplan-Meier method and log-rank tests. $\mathrm{P}<0.05$ was considered to indicate a statistically significant difference.

\section{Results}

circ-ASPH expression is elevated in GM and associated with an unfavorable prognosis. circRNA sequencing analysis revealed 128 circRNAs (fold-change $>2 ; \mathrm{P}<0.05$ ) that were differentially expressed between four pairs of GM and adjacent normal controls. The hierarchical clustering of the top 25 upregulated/downregulated circRNAs is shown in Fig. 1A. GM and non-cancerous tissues from the same four patients to verify the most upregulated circRNAs, including hsa_circRNA_102211, _101314,_104666,_001678,_100017 and _104634. Among these recruited candidates, hsa_circRNA_104634 was the most upregulated circRNA (Fig. 1B). hsa_circRNA_104634 was spliced from the ASPH gene (chr8:62593526-62596747) and the spliced length was 264 nucleotides. Thus, hsa circRNA_104634 was named circ-ASPH (Fig. 1C). The differential expression of circ-ASPH in GM was then explored in a large cohort of patients with GM $(n=60)$. The data revealed that the relative expression of circ-ASPH was significantly higher in GM specimens compared with in non-tumorous tissues $(\mathrm{P}<0.01$; Fig. 1D). In addition, total RNA was isolated, and RT-qPCR was used to measure circ-ASPH and linear ASPH mRNA expression after treatment with actinomycin D at different time points $(0,4,8,12$ and $24 \mathrm{~h})$. Linear ASPH mRNA had a shorter half-life compared with circ-ASPH, suggesting the stability of circ-ASPH (Fig. 1E). To further confirm the clinical relevance of circ-ASPH, Kaplan-Meier analysis was applied. The 60 patients with GM were divided into high- and low-circ-ASPH groups in accordance with the median expression level of circ-ASPH in cancer tissues. As a result, we found that upregulation of circ-ASPH in tissue samples was associated with lower overall survival rate for patients with GM after surgery (Fig. 1F). The expression of circ-ASPH in GM cell lines and NHAs was measured using RT-qPCR. The expression levels of circ-ASPH were significantly higher in U251 and LN229 cells compared with in NHAs (P<0.01; Fig. 1G). Two siRNAs targeting the back-spliced junction of circ-ASPH were used to silence circ-ASPH expression in LN229 cells (Fig. 1H).

circ-ASPH accelerates GM cell proliferation and aggressiveness. LN229 cells transfected with si-circ-ASPH-1 and si-circ-ASPH-2 both strongly downregulated the expression of
circ-ASPH (vs. si-NC, both $\mathrm{P}<0.01$; Fig. 2A). si-circ-ASPH-1 was chosen for further functional study because it has a stronger knockdown efficiency compared with si-circ-ASPH-2. Additionally, circ-ASPH expression was upregulated in U87MG cells due to its low circ-ASPH expression among the GM cell lines used in the present study. As a result, circ-ASPH expression was significantly upregulated after transfection with the circ-ASPH vector (vs. empty vector, $\mathrm{P}<0.01$; Fig. $2 \mathrm{~B}$ ). The CCK-8 and colony formation results suggested that cell viability was repressed by circ-ASPH-silencing in LN229 cells (Fig. 2C and D). In contrast, circ-ASPH-overexpression resulted in higher cell viability and more colonies formed in U87MG cells, suggesting the cell viability and proliferation-promoting role of circ-ASPH (Fig. 2C and D). Depletion of circ-ASPH significantly induced cell migratory potential inhibition in LN229 cells analyzed by wound healing and Transwell migration assays (both $\mathrm{P}<0.01$; Fig. $2 \mathrm{E}$ and F). circ-ASPH elevation increased U87MG cell migration compared with the empty vector group $(\mathrm{P}<0.05$ and $\mathrm{P}<0.001$; Fig. $2 \mathrm{E}$ and $\mathrm{F})$. Afterwards, cell invasion capacity was analyzed using a Matrigel invasion assay. It was found that cell invasion was markedly attenuated in cells transfected with si-circ-ASPH-1 compared with cells transfected with si-NC $(\mathrm{P}<0.01$; Fig. $2 \mathrm{~F})$. Moreover, increased circ-ASPH levels led to more U87MG cells passing through the Transwell membrane coated with Matrigel ( $\mathrm{P}<0.01$; Fig. 2F).

circ-ASPH sponges miR-599 to regulate AR expression in GM cells. circ-ASPH was primarily localized to the cytoplasm of LN229 and U87MG cell lines, as analyzed by a subcellular distribution assay, indicating that circ-ASPH functions at the post-transcriptional level (Fig. 3A). The potential interaction between circ-ASPH and miRNAs was predicted using starBase 2.0 and circular RNA interactome online databases. Only one miRNA, miR-599, was included in both databases (Fig. 3B). circ-ASPH was significantly enriched in the anti-Ago $2 \mathrm{immu}-$ noprecipitated pool compared with the anti-IgG pool $(\mathrm{P}<0.01)$. After knockdown of circ-ASPH, the enrichment was partially decreased in both LN229 and U87MG cells (anti-Ago2 si-NC vs. si-circ-ASPH-1; Fig. 3C). Additionally, overexpressed circ-ASPH elevated the efficiency of pull-down using biotin-labeled circ-ASPH probes (Fig. 3D). Moreover, miR-599 was enriched in the circ-ASPH pull-downs from LN229 and U87MG cells compared with the oligo probe group (both $\mathrm{P}<0.01$; Fig. 3E). Further dual-luciferase reporter assays indicated that miR-599 mimics markedly inhibited the luciferase signal of circ-ASPH wt but not circ-ASPH mut, compared with mimics-NC (Fig. 3F and G). Bioinformatics analysis predicted that AR is a potential target gene of miR-599. Moreover, the results suggested that AR mRNA expression was significantly elevated in GM cancerous tissue samples $(\mathrm{P}<0.01$; Fig. $3 \mathrm{H})$. Data from TCGA indicated that high expression of AR in GM tissues is associated with worse overall survival (Fig. 3I). Correlations between circ-ASPH and AR mRNA/miR-599 expression were further evaluated. A significant positive correlation between circ-ASPH and AR mRNA expression was identified $\left(\mathrm{R}^{2}=0.309, \mathrm{P}=0.011\right.$; Fig. $\left.3 \mathrm{~J}\right)$. However, the data failed to demonstrate the negative correlation between circ-ASPH and miR-599 expression (Fig. 3K). Next, upregulation of AR in GM cell lines was identified (Fig. 3L). AR downregulation induced 
A
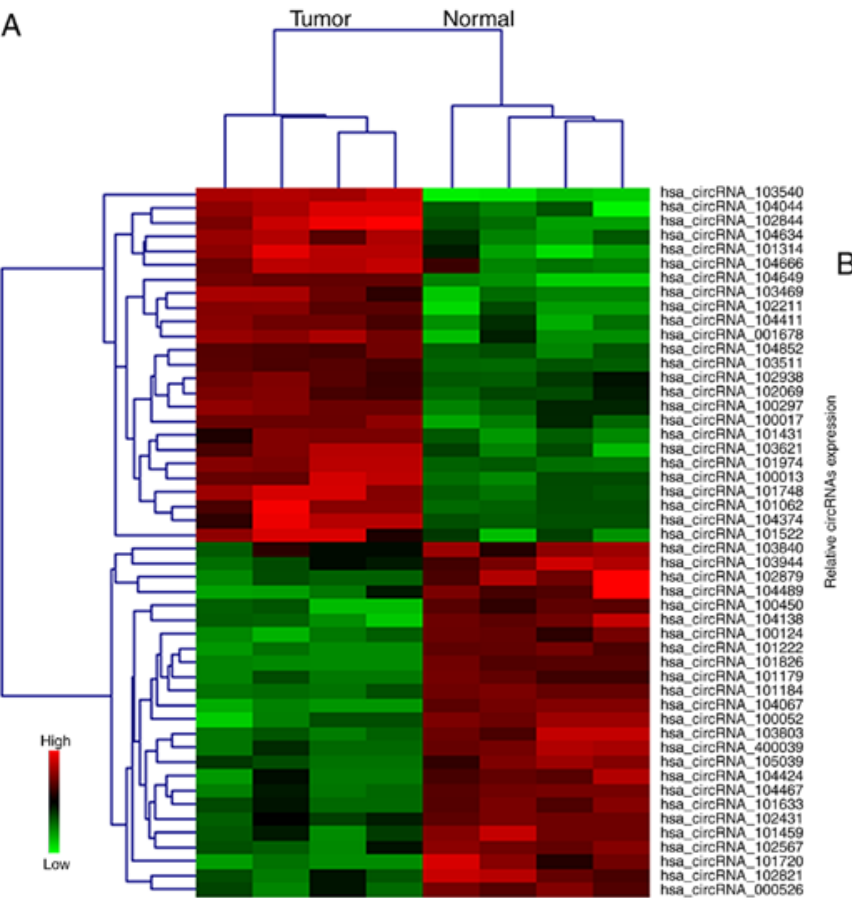

B

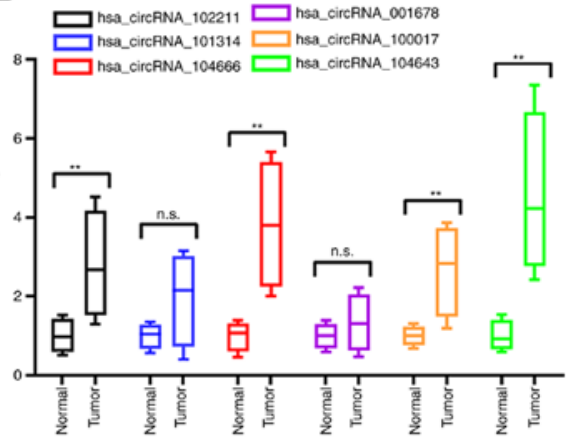

C

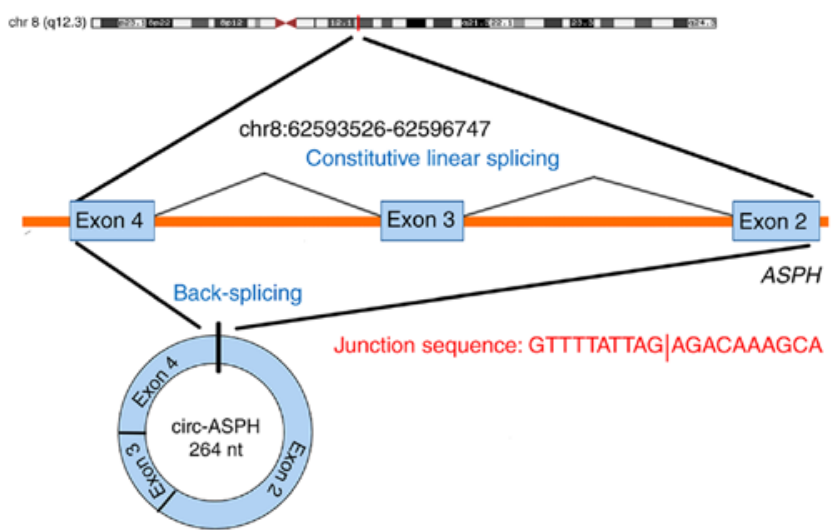

D

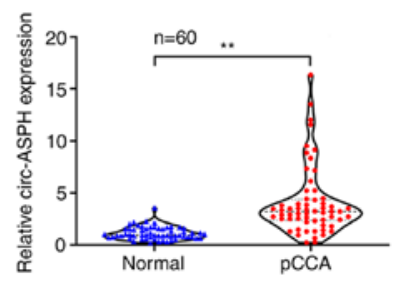

E

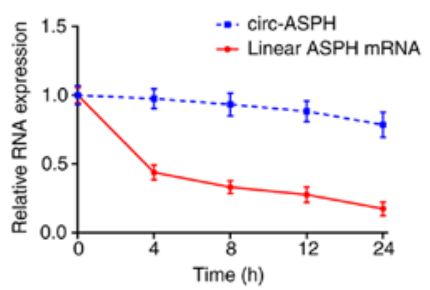

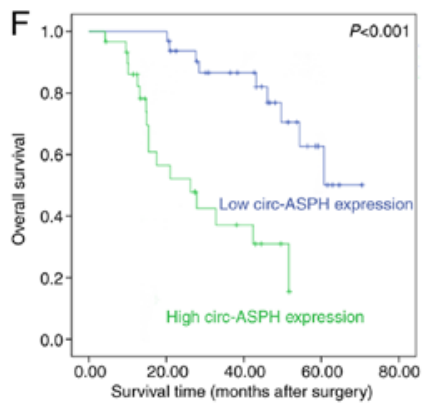

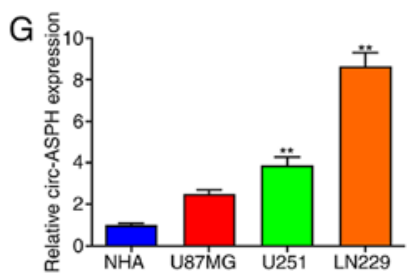

$\mathrm{H}$

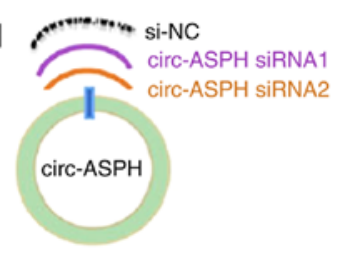

Figure 1. circ-ASPH expression in GM tissues and cells and its clinical value. (A) Clustered heatmap showing tissue-specific circRNAs. (B) RT-qPCR for hsa circRNA_102211,_101314,_104666,_001678,_100017 and_104634 expression in GM/non-cancerous specimens. (C) Schematic representation of circ-ASPH formation. (D) circ-ASPH expression in 60 pairs of GM/non-cancerous specimens by RT-qPCR. (E) Relative circ-ASPH and linear ASPH mRNA expression at different time points. (F) Kaplan-Meier analysis plots with log-rank test for overall survival in patients with GM according to circ-ASPH expression. (G) Relative expression of circ-ASPH in GM and NHA cells by RT-qPCR. (H) Schematic for two circ-ASPH siRNAs targeting to the back-spliced junction site of circ-ASPH. ${ }^{* *} \mathrm{P}<0.01$ vs. respective control. GM, glioma; circ, circular; hsa, Homo sapien; RT-q, reverse transcription-quantitative; NHA, normal human astrocyte; ASPH, aspartyl/asparaginyl $\beta$-hydroxylase. 

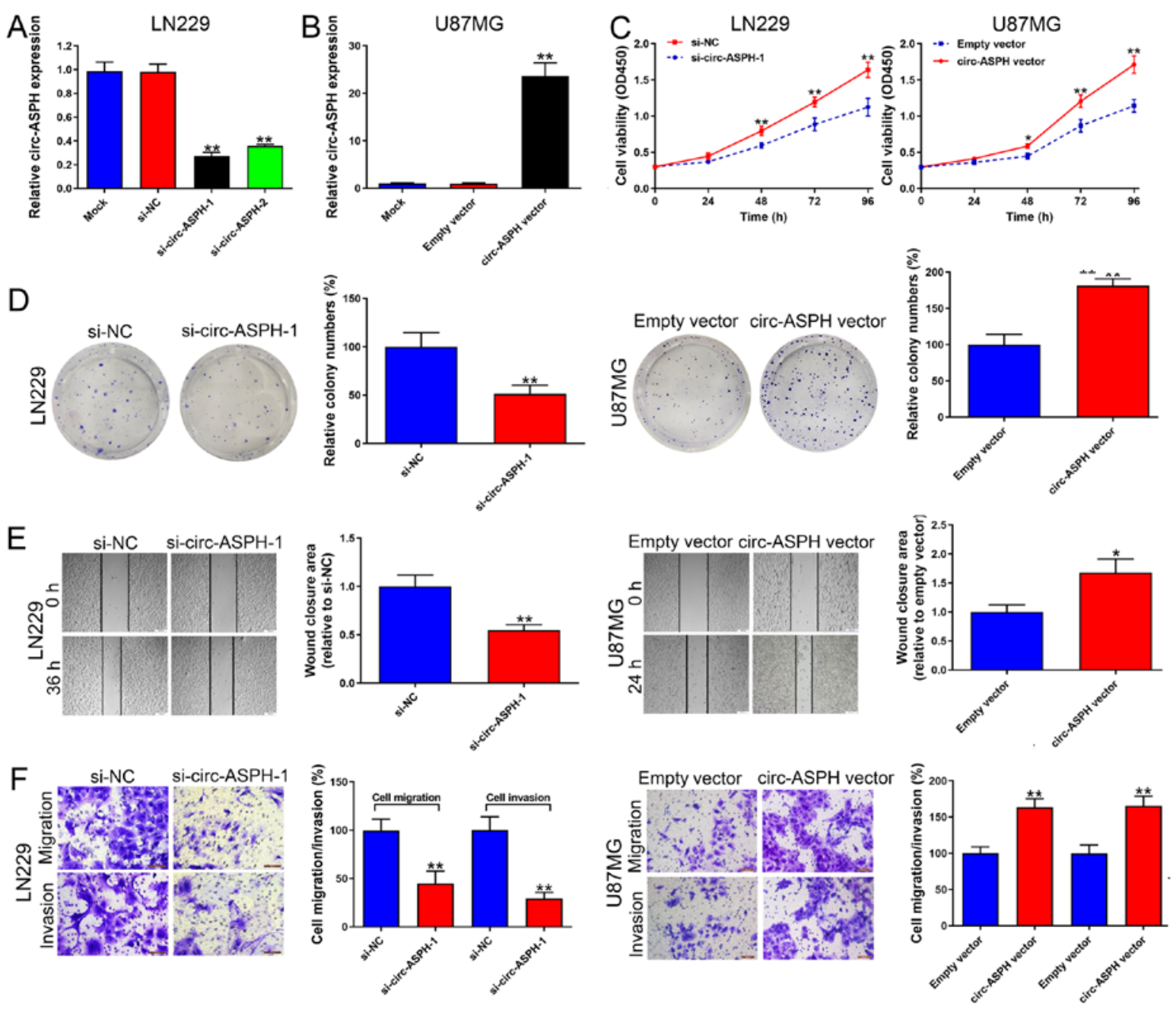

Figure 2. circ-ASPH facilitates GM cell proliferation and aggressiveness. (A) circ-ASPH expression was detected after transfection with si-NC, si-circ-ASPH-1 and si-circ-ASPH-2 in LN229 and U87MG cells by RT-qPCR. (B) circ-ASPH expression was detected after transfection with empty vector and circ-ASPH vector in LN229 and U87MG cells by RT-qPCR. (C) Cell viability was detected after transfection in LN229 and U87MG cells using a Cell Counting Kit-8 assay. (D) Clone forming was detected after transfection in LN229 and U87MG cells by colony formation assay. (E) Cell migration was detected after transfection in LN229 and U87MG cells by wound healing assay. (F) Cell migration and invasion was detected after transfection in LN229 and U87MG cells using a Transwell/Matrigel assay. ${ }^{~} \mathrm{P}<0.05$ and ${ }^{* *} \mathrm{P}<0.01$ vs. mock, si-NC or empty vector. GM, glioma; circ, circular; RT-q, reverse transcription-quantitative; si, small interfering; NC, negative control; ASPH, aspartyl/asparaginyl $\beta$-hydroxylase.

by miR-599 mimics was also validated. Conversely, cell transfection with the miR-599 inhibitor resulted in AR upregulation in U87MG cells compared with the inhibitor-NC $(\mathrm{P}<0.01$; Fig. 3M). A dual-luciferase reporter assay demonstrated an inhibition of the luciferase activity of AR mRNA 3'-UTR wt, but did not change the luciferase intensity of AR mRNA 3'-UTR mut, confirming that AR mRNA 3'-UTR interacted with miR-599 (Fig. 3N and O).

circ-ASPH facilitates cell proliferation and invasion by regulating $A R$ expression. To further verify whether the oncogenic function of circ-ASPH is partly attributed to its regulation of AR, a rescue assay was performed. As Fig. 4A indicates, silencing circ-ASPH attenuated AR expression levels compared with si-NC. However, this effect could be partly reversed by cotransfection with si-circ-ASPH-1 and AR vector. Moreover, overexpression of circ-ASPH led to enhanced expression of AR. Further cotransfection with the circ-ASPH vector and si-AR partly inhibited AR expression (Fig. 4A). For the functional assay, CCK-8, clone-forming and Transwell invasion assays showed that silencing of circ-ASPH attenuated cell proliferation, clone formation and cell invasion in LN229 cells. Meanwhile, cotransfection with si-circ-ASPH-1 and AR vector partly promoted cell proliferation, colony formation and cell invasive capacity (Fig. 4B-D). For U87MG cells, overexpression of circ-ASPH contributed to cell proliferation, clone forming and cell invasion. After cotransfection with circ-ASPH vector and si-AR, the cell viability, colony formation ability and invaded cells were partially decreased (Fig. 4B-D).

AR activates SOCS2-AS1 expression in GM cells. AR functions as a steroid hormone-activated transcription factor (19). A previous study reported its downstream targets in various malignancies, such as prostate cancer (20). The present study focused on IncRNAs that have been reported as targets of AR in other cancer types, including TMPO-AS1 (21), LINC00304 (22), PRCAT38 (23), ARLNC1 (24), GAS5 (25), SOCS2-AS1 (13), and ZEB1-AS1 (26) (Fig. 5A). It was identified that only the expression of SOCS2-AS1 was increased after AR overexpression (Fig. 5B). Consistent with 

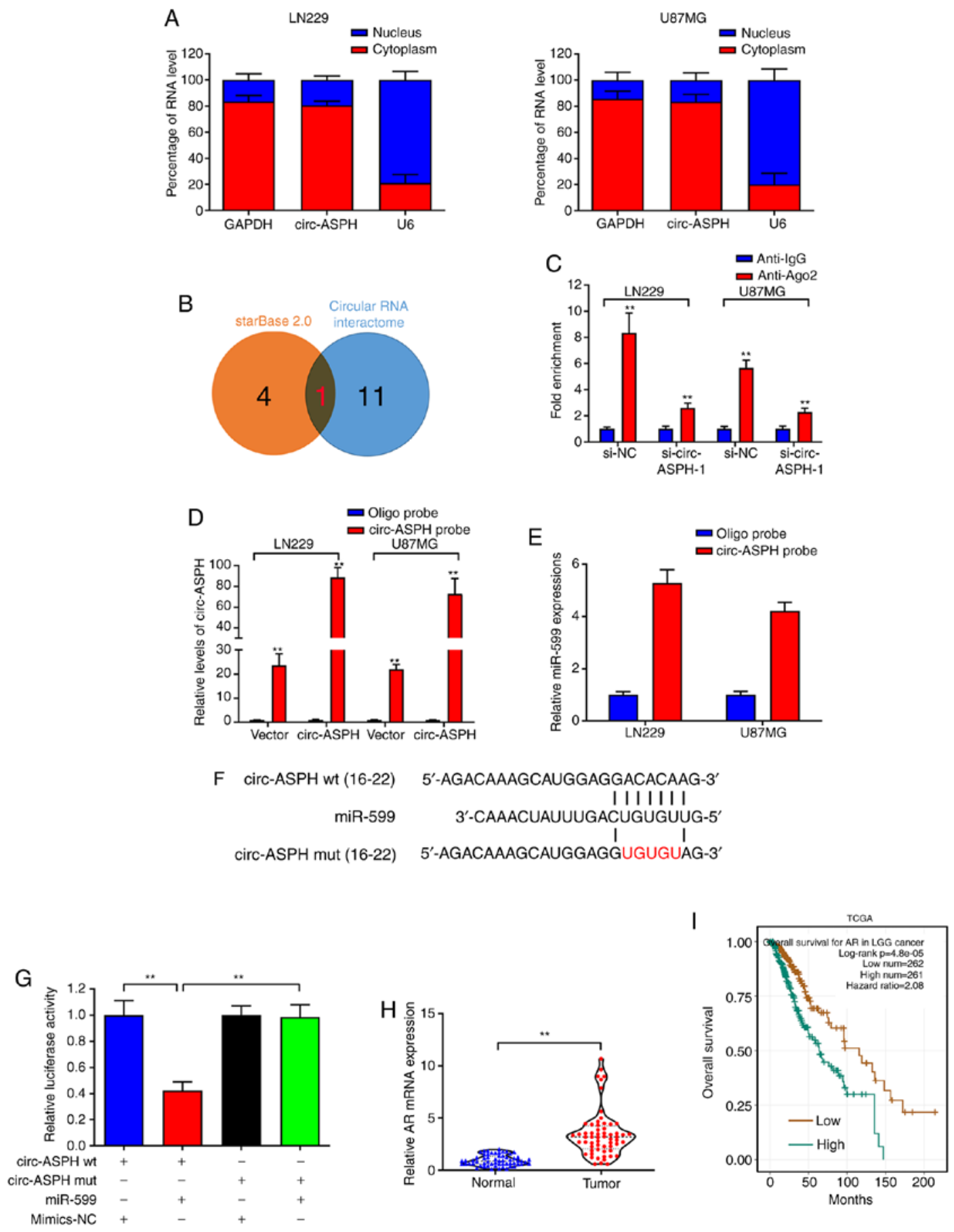

Figure 3. Continued.

expectations, decreased AR markedly inhibited SOCS2-AS1 expression (Fig. 5C). There was a positive correlation between circ-ASPH and SOCS2-AS1 expression $\left(\mathrm{R}^{2}=0.729\right.$; Fig. 5D). However, there was no correlation between AR mRNA and SOCS2-AS1 expression (Fig. 5E). SOCS2-AS1 downregulation induced by si-circ-ASPH-1 was validated. Similarly, elevated circ-ASPH led to enhanced expression of SOCS2-AS1 ( $\mathrm{P}<0.01$; Fig. 5F).

\section{Discussion}

Recently, circRNAs have been clarified to regulate a number important processes, such as metastasis, differentiation and metabolism, leading to the progression of several diseases including malignant tumors (27). In previous studies, several circRNAs such as circ-FBXW7, circ-KIF4A and circ-TTBK2 have been proven to play essential functions in GM tumorigenesis (28-30). In the present study, a circRNA microarray was conducted to study the expression profile in GM. A total of 128 circRNAs with different expression levels were identified. The top six upregulated circRNAs, namely hsa_circRNA_102211,_101314,_104666,_001678,_100017 and _104634, were analyzed using RT-qPCR. Among these circRNAs, hsa_circRNA_104634 was the most upregulated. hsa_circRNA_104634 is spliced from exons 2-4 of the ASPH gene (31). Kaplan-Meier analysis with the log-rank test 

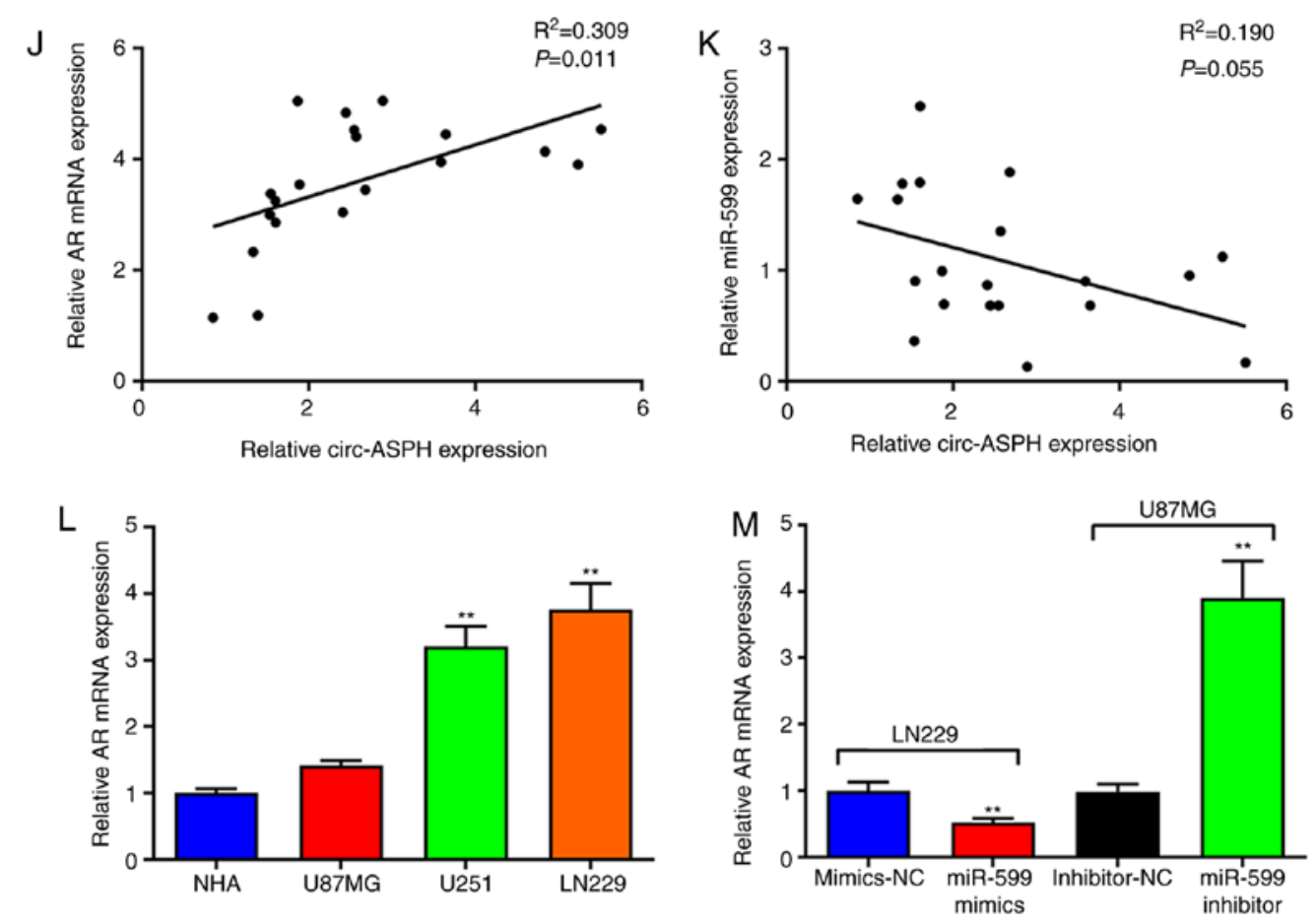

N AR mRNA 3'-UTR wt (site1)

5'-CUCUGUGCCAGCCACACAAA-3'

| | | | |

miR-599 3'-CAAACUAUUUGACUGUGUUG-5'

AR mRNA 3'-UTR mut 5'-CUCUGUGCCAGCCAGUGUAA-3'

AR mRNA 3'-UTR wt (site2) 5'-GGAAAAAUAGCCUACACAAG-3'

| | | | | |

miR-599 3'-CAAACUAUUUGACUGUGUUG-5'

AR mRNA 3'-UTR mut 5'-GGAAAAUAGCCUAGUGUAG-3'

Site 1
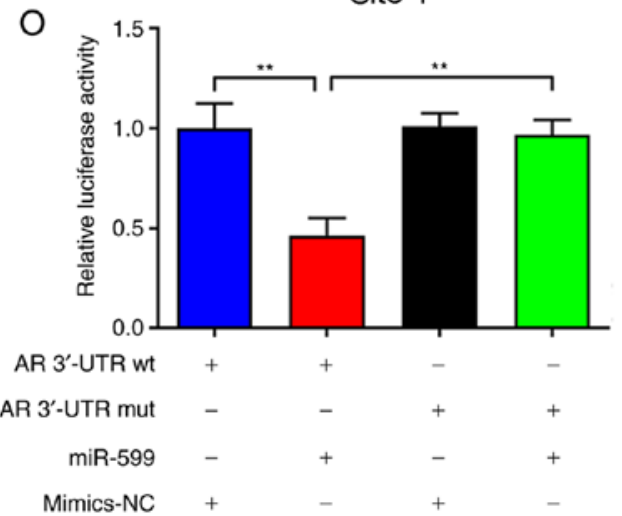

Site 2

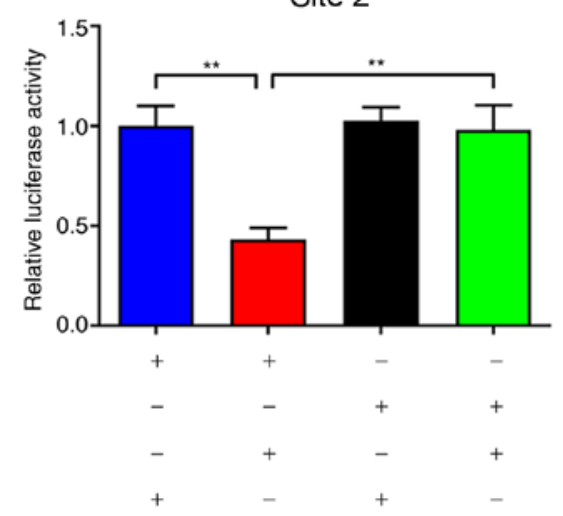

Figure 3. circ-ASPH sponges miR-599 to upregulate AR expression in GM. (A) RT-qPCR detection of the percentage of circ-ASPH in the cytoplasmic and nuclear fractions of LN229 and U87MG cells. (B) miRNAs that may be sponged by circ-ASPH were predicted using the starBase 2.0 and circRNA interactome databases. (C) Ago2-RNA immunoprecipitation assay for circ-ASPH levels in LN229 and U87MG cells after transfection. (D) Lysates prepared from LN229 and U87MG cells after transfection were subjected to RNA pull-down assay. (E) RT-qPCR for miR-599 expression in LN229 and U87MG cell lysates. (F) Schematic illustration of circ-ASPH-wt and circ-ASPH-mut luciferase reporter vectors. (G) Binding ability between circ-ASPH and miR-599 was detected by dual-luciferase reporter assay in 293T cells. (H) Relative AR expression in GM/non-cancerous tissues analyzed using a TCGA dataset. (I) Kaplan-Meier analysis for overall survival in patients with GM according to AR expression in a TCGA dataset. (J and K) Correlation analysis of circ-ASPH, miR-599 and AR mRNA expression was explored in GM tissue samples. (L) Relative AR mRNA expression in GM and NHA cells was detected by RT-qPCR. (M) Relative AR mRNA expression was detected after transfection in LN229 and U87MG cells by RT-qPCR. (N and O) Binding ability between AR mRNA 3'-UTR and miR-599 was detected by dual-luciferase reporter assay in $293 \mathrm{~T}$ cells. ${ }^{* *} \mathrm{P}<0.01$ vs. respective control. GM, glioma; circ, circular; RT-q, reverse transcription-quantitative; miRNA/miR, microRNA; TCGA, The Cancer Genome Atlas; NHA, normal human astrocytes; UTR, untranslated region; wt, wild-type; mut, mutant; ASPH, ASPH, aspartyl/asparaginyl $\beta$-hydroxylase.

identified circ-ASPH as a prognostic indicator for patients with GM. Nevertheless, the independent prognostic role of
circ-ASPH was not investigated because the clinical characteristics of several patients were incomplete. 
A

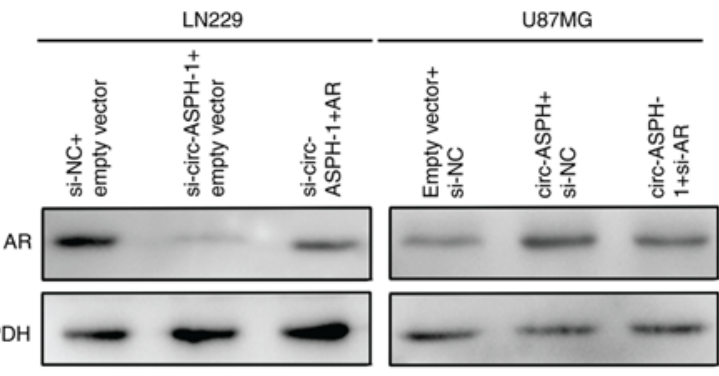

B

LN229
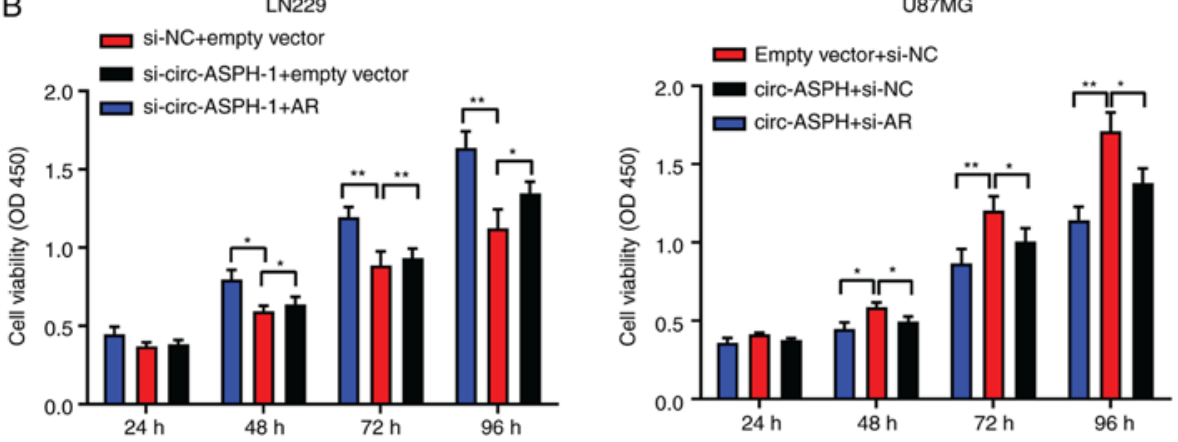

C
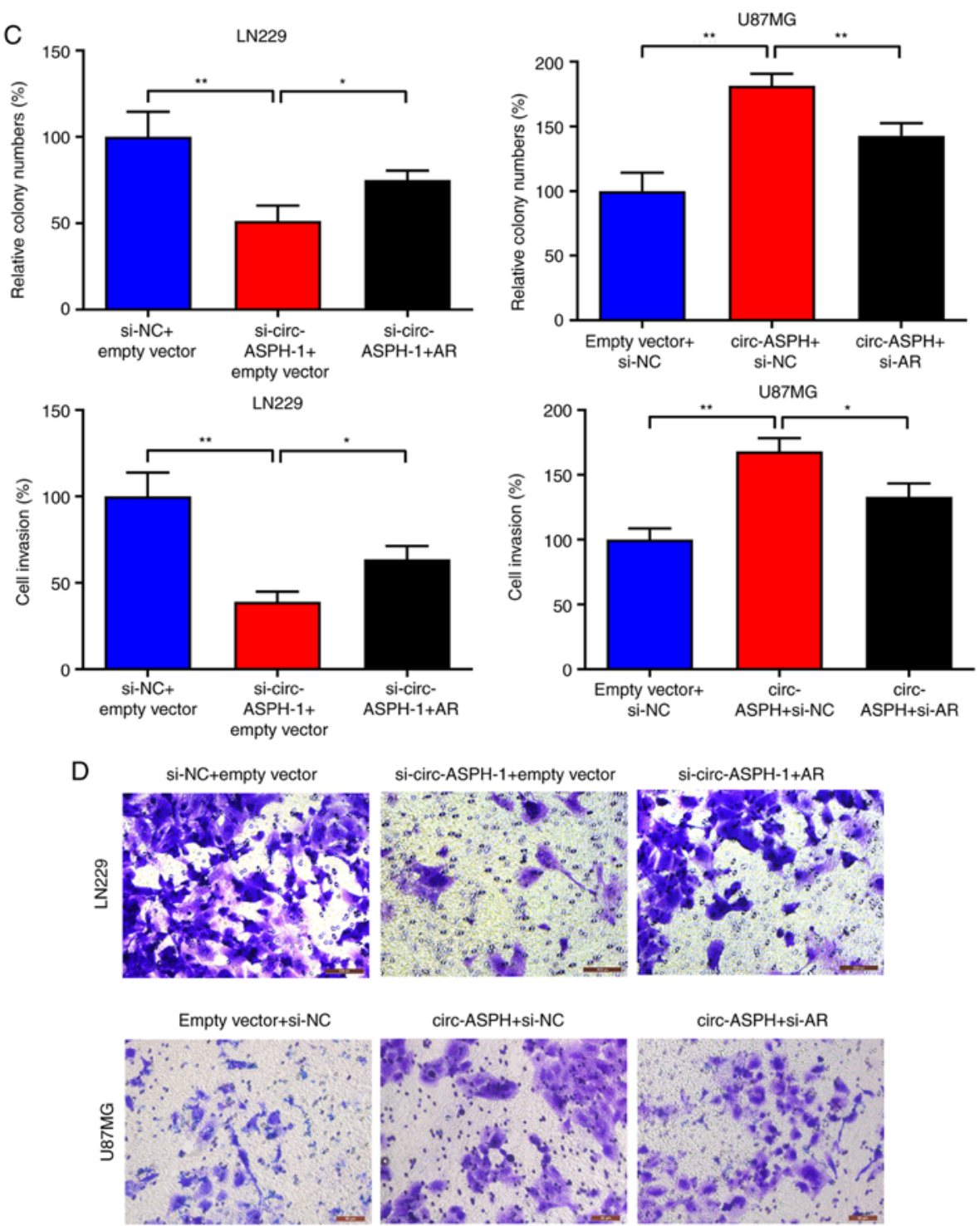

Figure 4. circ-ASPH contributes to glioma progression by regulating AR expression. (A) Protein level of AR was measured by western blotting after transfection in LN229 and U87MG cells. (B) A Cell Counting Kit-8 assay was performed to analyze the viability of LN229 and U87MG cells after transfection. (C) A colony formation assay was performed to detect the clone forming ability of LN229 and U87MG cells after transfection. (D) A Transwell assay was performed to detect the migration and invasion of LN229 and U87MG cells after transfection. " $\mathrm{P}<0.05$ and ${ }^{* *} \mathrm{P}<0.01$ vs. respective control. circ, circular; si, small interfering; $\mathrm{NC}$, negative control; ASPH, aspartyl/asparaginyl $\beta$-hydroxylase. 

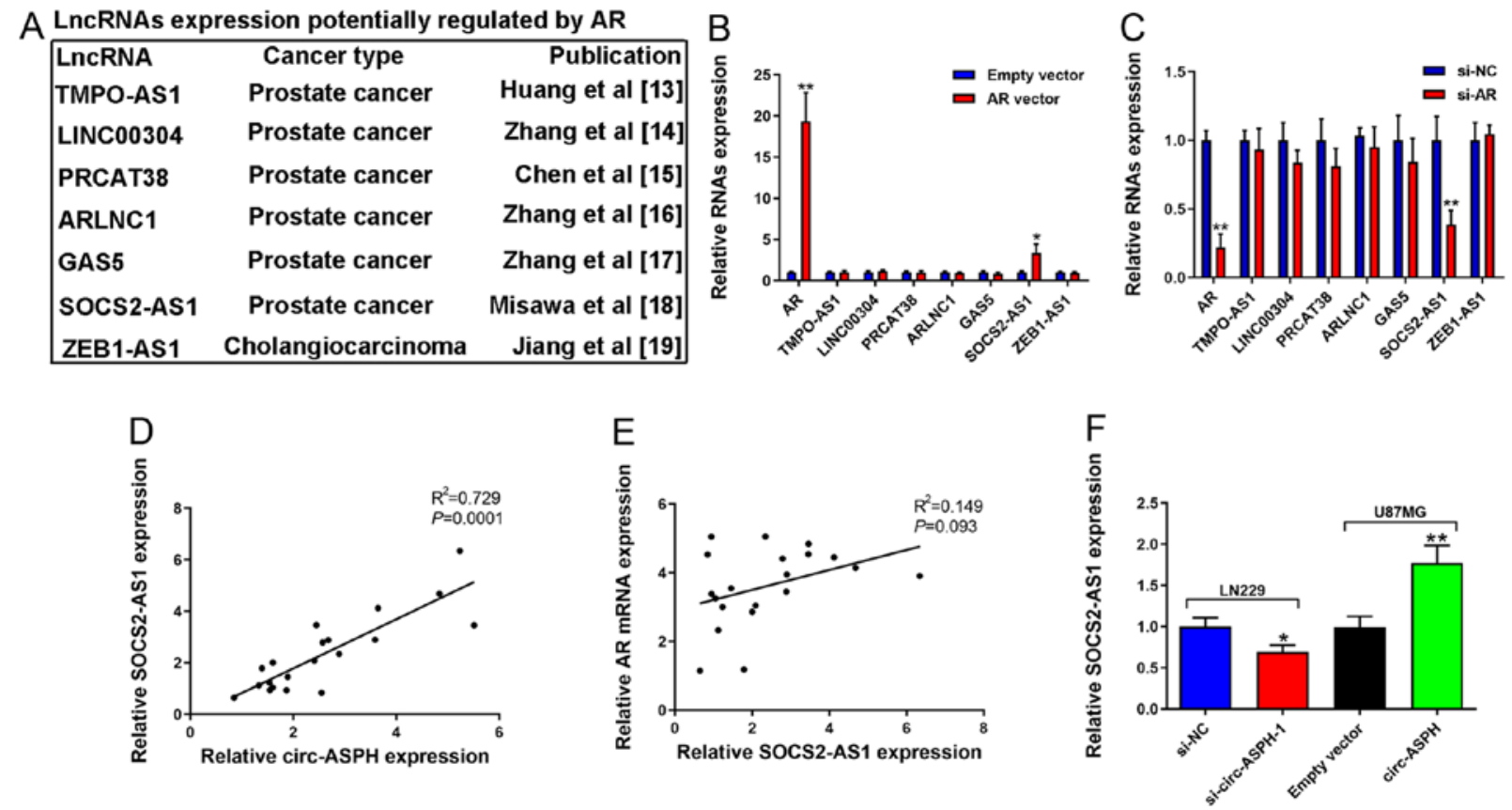

Figure 5. AR activates SOCS2-AS1 expression. (A) Potential lncRNAs that may be regulated by AR are summarized. (B and C) RT-qPCR for lncRNAs expression after AR upregulation/downregulation in LN229 cells. (D and E) Correlation analysis of circ-ASPH, AR mRNA and SOCS2-AS1 expression was explored in glioma tissue samples. (F) Relative SOCS2-AS1 expression was detected after transfection in LN229 and U87MG cells by RT-qPCR. " $\mathrm{P}<0.05$ and ${ }^{* *} \mathrm{P}<0.01$ vs. respective control. lnc., long non-coding; RT-q, reverse transcription-quantitative; NC, negative control; si, small interfering; ASPH, aspartyl/asparaginyl $\beta$-hydroxylase.

After confirming the expression levels of circ-ASPH and its clinical relevance, a series of functional assays were performed to determine its functions in GM cells. LN229 and U87MG cells were selected for further study. The data illustrated that decreased circ-ASPH inhibited GM cell proliferation, migration and invasiveness and vice versa. The localization of circRNAs suggests how they exert their functions (32). circ-ASPH is primarily localized to the cytoplasm, which suggests that it has mechanisms in post-transcriptional gene regulation (33). Several studies have determined the importance of miR-599 in suppressing cancer progression, such as gastric cancer and esophageal squamous cell carcinoma $(34,35)$. Moreover, miR-599 functions as a tumor suppressor by targeting Ras-related protein Rab-27B and periostin in glioma $(36,37)$. The present study demonstrated that circ-ASPH counteracts miR-599-mediated AR suppression by acting as a sponge for miR-599, which broadens the understanding of the functions of miR-599. AR is a steroid hormone-activated transcription factor (19). Upon binding the hormone ligand, the receptor dissociates from accessory proteins, translocates into the nucleus, dimerizes and then stimulates transcription of androgen responsive genes (20). The current study identified that the oncogenic role of circ-ASPH is partially dependent on its regulation of AR. IncRNAs, including TMPO-AS1 (21), LINC00304 (22), PRCAT38 (23), ARLNC1 (24), GAS5 (25), SOCS2-AS1 (13), and ZEB1-AS1 (26), have been identified as direct targets of AR in other malignancies, including prostate cancer (21-25) and cholangiocarcinoma (26). Among these lncRNAs, only SOCS2-AS1 expression was regulated by AR in GM, suggesting a tissue-specific mechanism of AR. SOCS2-AS1 is a well-known lncRNA that promotes prostate cancer cell development and progression (13). Furthermore, SOCS2-AS1 was also positively regulated by circ-ASPH in the present study. Therefore, circ-ASPH/miR-599/AR/SOCS2-AS1 signaling functions in GM progression.

In conclusion, circ-ASPH counteracted miR-599-mediated AR suppression by acting as a sponge for miR-599. Furthermore, AR positively regulated lncRNA SOCS2-AS1 expression levels in GM. Taken together, these data suggested that the circ-ASPH/miR-599/AR/SOCS2-AS1 axis may be a promising molecular target for GM.

\section{Acknowledgements}

Not applicable.

\section{Funding}

No funding was received.

\section{Availability of data and materials}

All data generated or analyzed during the study are included in this published article. The additional datasets generated and/or analyzed during the current study are available in The Cancer Genome Atlas repository, (https://www.cancer. gov/about-nci/organization/ccg/research/structural-genomics/tcga/ using-tcga).

\section{Authors' contributions}

YQ conceived and designed the study. YQ and JZ analyzed and interpreted the data. YQ, LQ, and LH performed the in vitro assays. YQ and LQ were major contributors in drafting the 
manuscript. YQ and LQ confirmed the authenticity of all the raw data. All authors read and approved the final manuscript.

\section{Ethics approval and consent to participate}

The study was authorized by the Ethics Committee of Qiqihar Hospital Affiliated to Southern Medical University and written informed consent was acquired from each patient.

\section{Patient consent for publication}

Not applicable.

\section{Competing interests}

The authors declare that they have no competing interests.

\section{References}

1. Ostrom QT, Gittleman H, Xu J, Kromer C, Wolinsky Y, Kruchko C and Barnholtz-Sloan JS: CBTRUS statistical report: Primary brain and other central nervous system tumors diagnosed in the United States in 2009-2013. Neuro Oncol 18 (Suppl_5): v1-v75, 2016.

2. Ostrom QT, Cote DJ, Ascha M, Kruchko C and Barnholtz-Sloan JS Adult glioma incidence and survival by race or ethnicity in the United States from 2000 to 2014. JAMA Oncol 4: 1254-1262, 2018

3. Jiang T, Nam DH, Ram Z, Poon WS, Wang J, Boldbaatar D, Mao Y, Ma W, Mao Q, You Y, et al: CGCG clinical practice guidelines for the management of adult diffuse gliomas. Cancer Lett 375: 263-273, 2016.

4. Rybak-Wolf A, Stottmeister C, Glažar P, Jens M, Pino N, Giusti S Hanan M, Behm M, Bartok O, Ashwal-Fluss R, et al: Circular RNAs in the mammalian brain are highly abundant, conserved, and dynamically expressed. Mol Cell 58: 870-885, 2015.

5. Bolha L, Ravnik-Glavač M and Glavač D: Circular RNAs: Biogenesis, function, and a role as possible cancer biomarkers. Int J Genomics 2017: 6218353, 2017.

6. Conn SJ, Pillman KA, Toubia J, Conn VM, Salmanidis M Phillips CA, Roslan S, Schreiber AW, Gregory PA and Goodall GJ: The RNA binding protein quaking regulates formation of circRNAs. Cell 160: 1125-1134, 2015

7. Xu Y, Yao Y, Zhong X, Leng K, Qin W, Qu L, Cui Y and Jiang X: Downregulated circular RNA hsa_circ_0001649 regulates proliferation, migration and invasion in cholangiocarcinoma cells. Biochem Biophys Res Commun 49: 455-461, 2018.

8. Zhang SJ, Chen X, Li CP, Li XM, Liu C, Liu BH, Shan K, Jiang Q, Zhao C and Yan B: Identification and characterization of circular RNAs as a new class of putative biomarkers in diabetes retinopathy. Invest Ophthalmol Vis Sci 58: 6500-6509, 2017.

9. Wang W, Wang Y, Piao H, Li B, Huang M, Zhu Z, Li D, Wang T, $\mathrm{Xu} \mathrm{R}$ and Liu K: Circular RNAs as potential biomarkers and therapeutics for cardiovascular disease. PeerJ 7: e6831, 2019.

10. Jin P, Huang Y, Zhu P, Zou Y, Shao T and Wang O: CircRNA circHIPK3 serves as a prognostic marker to promote glioma progression by regulating miR-654/IGF2BP3 signaling. Biochem Biophys Res Commun 503: 1570-1574, 2018.

11. Chen J, Chen T, Zhu Y,Li Y,Zhang Y, Wang Y,Li X, Xie X, Wang J, Huang M, et al: circPTN sponges miR-145-5p/miR-330-5p to promote proliferation and stemness in glioma. J Exp Clin Cance Res 38: 398, 2019.

12. Rahim B and O'Regan R: AR Signaling in breast cancer. Cancers (Basel) 9: 21, 2017

13. Misawa A, Takayama K, Urano T and Inoue S: Androgen-induced long noncoding RNA (lncRNA) SOCS2-AS1 promotes cell growth and inhibits apoptosis in prostate cancer cells. J Biol Chem 291: 17861-17880, 2016

14. Su H, Lin F, Deng X, Shen L, Fang Y, Fei Z, Zhao L, Zhang X, Pan H, Xie D, et al: Profiling and bioinformatics analyses reveal differential circular RNA expression in radioresistant esophageal cancer cells. J Transl Med 14: 225, 2016.

15. Livak KJ and Schmittgen TD: Analysis of relative gene expression data using real-time quantitative PCR and the 2(-Delta Delta C(T)) method. Methods 25: 402-408, 2001
16. Dudekula DB, Panda AC, Grammatikakis I, De S, Abdelmohsen K and Gorospe M: CircInteractome: A web tool for exploring circular RNAs and their interacting proteins and microRNAs. RNA Biol 13: 34-42, 2016.

17. Li JH, Liu S, Zhou H, Qu LH and Yang JH: starBase v2.0: Decoding miRNA-ceRNA, miRNA-ncRNA and protein-RNA interaction networks from large-scale CLIP-Seq data. Nucleic Acids Res 42: D92-D97, 2014.

18. Qu Y, Zhu J, Liu J and Qi L: Circular RNA circ_0079593 indicates a poor prognosis and facilitates cell growth and invasion by sponging miR-182 and miR-433 in glioma. J Cell Biochem 120: $18005-18013,2019$.

19. Gucalp A and Traina TA: The Androgen Receptor: Is it a promising target? Ann Surg Oncol 24: 2876-2880, 2017.

20. Schweizer MT and Yu EY: AR-signaling in human malignancies: Prostate cancer and beyond. Cancers (Basel) 9: 7, 2017.

21. Huang W, Su X, Yan W, Kong Z, Wang D, Huang Y, Zhai Q, Zhang $\mathrm{X}, \mathrm{Wu} \mathrm{H}, \mathrm{Li} \mathrm{Y}$, et al: Overexpression of AR-regulated IncRNA TMPO-AS1 correlates with tumor progression and poor prognosis in prostate cancer. Prostate 78: 1248-1261, 2018.

22. Zhang P, Lu Y, Kong Z, Zhang Y, Fu F, Su X, Huang Y, Wan X and Li Y: Androgen-responsive lncRNA LINC00304 ppromotes cell cycle and proliferation via regulating CCNA1. Prostate 79: 994-1006, 2019.

23. Chen Z, Song X, Li Q, Xie L, Guo T, Su T, Tang C, Chang X, Liang B and Huang D: Androgen receptor-activated enhancers simultaneously regulate oncogene TMPRSS2 and lncRNA PRCAT38 in prostate cancer. Cells 8: 864, 2019.

24. Zhang Y, Pitchiaya S, Cieślik M, Niknafs YS, Tien JC, Hosono Y, Iyer MK, Yazdani S, Subramaniam S, Shukla SK, et al: Analysis of the androgen receptor-regulated lncRNA landscape identifies a role for ARLNC1 in prostate cancer progression. Nat Genet 50: 814-824, 2018.

25. Zhang Y, Su X, Kong Z, Fu F, Zhang P, Wang D, Wu H, Wan X and Li Y: An androgen reduced transcript of lncRNA GAS5 promoted prostate cancer proliferation. PLoS One 12: e0182305, 2017.

26. Jiang X, Li J, Wang W, Hu Z, Guan C, Zhao Y, Li W and Cui Y: AR-induced ZEB1-AS1 represents poor prognosis in cholangiocarcinoma and facilitates tumor stemness, proliferation and invasion through mediating miR-133b/HOXB8. Aging (Albany NY) 12: 1237-1255, 2020.

27. Zhang HD, Jiang LH, Sun DW, Hou JC and Ji ZL: CircRNA: A novel type of biomarker for cancer. Breast Cancer 25: 1-7, 2018.

28. Gao ZG, Yang P, Huang J and Ding YQ: CircFBXW7 alleviates glioma progression through regulating miR-23a-3p/PTEN axis. Anat Rec (Hoboken) 304: 279-290, 2021.

29. Huo LW, Wang YF, Bai XB, Zheng HL and Wang MD: circKIF4A promotes tumorogenesis of glioma by targeting miR-139-3p to activate Wnt5a signaling. Mol Med 26: 29, 2020

30. Zhang HY, Zhang BW, Zhang ZB and Deng QJ: Circular RNA TTBK2 regulates cell proliferation, invasion and ferroptosis via miR-761/ITGB8 axis in glioma. Eur Rev Med Pharmacol Sci 24: 2585-2600, 2020

31. Glažar P, Papavasileiou P and Rajewsky N: circBase: A database for circular RNAs. RNA 20: 1666-1670, 2014

32. Yang Q, Li F, He AT and Yang BB: Circular RNAs: Expression, localization, and therapeutic potentials. Mol Ther: Jan 21, 2021 (Epub ahead of print). doi: 10.1016/j.ymthe.2021.01.018.

33. Mumtaz PT, Taban Q, Dar MA, Mir S, Haq ZU, Zargar SM, Shah RA and Ahmad SM: Deep insights in circular RNAs: From biogenesis to therapeutics. Biol Proced 22: 10, 2020.

34. Li C, Tian Y, Liang Y and Li Q: Circ 0008035 contributes to cell proliferation and inhibits apoptosis and ferroptosis in gastric cancer via miR-599/EIF4A1 axis. Cancer Cell Int 20: 84, 2020.

35. Ba Y, Liu Y, Li C, Zhu Y and Xing W: HIPK3 promotes growth and metastasis of esophageal squamous cell carcinoma via regulation of miR-599/c-MYC axis. Onco Targets Ther 13 1967-1978, 2020

36. Jiang Y, Wang X, Zhang J and Lai R: MicroRNA-599 suppresses glioma progression by targeting RAB27B. Oncol Lett 16: 1243-1252, 2018.

37. Zhang T, Ma G, Zhang Y, Huo H and Zhao Y: miR-599 inhibits proliferation and invasion of glioma by targeting periostin. Biotechnol Lett 39: 1325-1333, 2017.

This work is licensed under a Creative Commons Attribution-NonCommercial-NoDerivatives 4.0 International (CC BY-NC-ND 4.0) License. 